\title{
Preliminary investigation for the identification of Sri Lankan Cinnamomum species using randomly amplified polymorphic DNA (RAPD) and sequence related amplified polymorphic (SRAP) markers
}

\author{
P.D. Abeysinghe ${ }^{1 *}$, N.G.C.D. Samarajeewa ${ }^{1}$, G. Li $^{2}$ and K.G.G. Wijesinghe ${ }^{3}$ \\ ${ }^{I}$ Department of Botany, Faculty of Science, University of Ruhuna, Matara. \\ ${ }^{2}$ Department of Plant Science, University of Manitoba, Winnipeg, Canada. \\ ${ }^{3}$ Cinnamon Research Station, Department of Export Agriculture, Palolpitiya, Matara.
}

\begin{abstract}
Cinnamon is one of the important minor export crops in Sri Lanka. Cinnamomum verum Presl is known as true cinnamon and seven other wild Cinnamomum spp. such as C. dubium Nees, C. citriodorum Thw., C. capparucoronde Blume, C. litseaefolium Thw., C. ovalifolium Weight, C. rivulorum Kostermans and C. sinharajaense Kostermans are native to Sri Lanka. The identification of Cinnamomum species is still based on morphological characters, which are influenced by environmental factors. Therefore, molecular markers such as randomly amplified polymorphic DNA (RAPD) and sequence related amplified polymorphism (SRAP) were employed in order to find a more reliable approach to identify Cinnamomum species correctly. Using RAPD and SRAP techniques, it was possible to detect the polymorphism as well as to identify the Cinnamomum species. Fourteen RAPD primers and 20 sets of SRAP primer combinations gave amplification products. However, one set of SRAP primer combinations produced more markers for Cinnamomum species than the RAPD markers. Amplification products from both techniques could be categorized as genus specific, species specific and intra-species specific markers. Both polymerase chain reaction (PCR) based techniques employed in this study can be used to identify the species, to estimate the genetic diversity of Cinnamomum spp. and to detect polymorphism, which could be used to screen the accessions of germplasm collected at the Department of Export Agriculture, Sri Lanka.
\end{abstract}

Keywords: Cinnamomum spp., cinnamon, RAPD, SRAP, Sri Lanka.

\section{INTRODUCTION}

The genus Cinnamomum belongs to Family Lauraceae. It consists of about 250 species distributed in the South, East and South East Asia and Australia (Kostermans, 1995). Cinnamomum verum Presl known as true cinnamon is one of the important spice crops in Sri Lanka. In addition to $C$. verum Presl, the genus includes several other important wild cinnamon species such as C. capparucoronde, C. citriodorum, C. dubium, C. litseafolium, C. ovalifolium, $C$. rivulorum and $C$. sinharajanse (Sritharan, 1984), reported to be present in Sri Lanka. Currently, the extent of cinnamon cultivation in Sri Lanka is around $29450 \mathrm{ha}$, which contributes to $60-70 \%$ of the total world production (Anon, 2006). Although C. verum is the main commercial species, other species of Cinnamomum are reported to have medicinal and ethno-botanical values (Krishnamoorthy et al., 1997; Khan et al., 2003; Bruno, 2009; Kumarathilake et al., 2010; Smerq \& Sharma, 2011).

Morphological characters (leaf and floral characters) are used to identify Cinnamomum species in Sri Lanka, particularly for field identification. Morphological features such as leaf length (L), breadth (B), area, petiole length, apex angle $\left(\mathrm{A}^{\circ}\right)$, base angle $\left(\mathrm{B}^{\circ}\right)$ and mean $\mathrm{B}^{\circ} / \mathrm{A}^{\circ}$ are useful in characterizing the Cinnamomum species. Among the wild species, leaf length, breadth and petiole length was the highest in $C$. sinharajanse and lowest in C. ovalifolium (Sritharan, 1984). The mean L/B ratio was found to be a useful parameter to separate the species from one another, e.g. C. capparu-coronde and C. rivulorum had values $>3$, while $C$. ovalifolium and unidentified individuals had values between 1 and 2 and the rest 
had values between 2 and 3 (Sritharan, 1984). Some of these species are significantly different from each other and can be easily distinguished by examining the leaf morphological characters, e.g. C. dubium has densely grey-tomentellous flush, midrib and two prominent basal lateral veins running out below the acumen to almost the tip of leaf. The flush of $C$. liseaefolium is silverysericeous, the midrib of the leaves are faint and the two basal or sub-basal veins terminate at the middle of leaf. Leaf shapes are quite different even within a species, e.g. leaf shape of $C$. verum, can vary from oval or elliptical to lanceolate-oval or narrowly elliptical (Dassanayaka et al., 1995).

Many studies of these species are based on the identification of floral and pollen morphology, ecophysiological features, chemical and essential oil constituents etc. (Joshep, 1981; Wijesinghe et al., 2004; Dighe et al., 2005; Saumyasiri et al., 2006). Among the Cinnamomum species the largest size of pollen was recorded from $C$. verum $(26.23 \pm 0.24 \mu \mathrm{m})$ and the smallest (17.62 $\pm 0.14 \mu \mathrm{m})$ from C. dubium (Sritharan, 1984). Based on the stomatal indices, Cinnamomum species can be categorized into 3 groups, those with the lowest stomatal index: $18-19$ (C. sinharajanse, $C$. revulorum and $C$. capparu coronde), the highest stomatal index: $25-27$ (C. ovalifolium and C. liseaefolium), and medium stomatal index: 22 (C. verum and $C$. dubium).

Considering the above facts, the identification of Cinnamomum species using only morphological and floral characters has difficulties and may lead to controversy. Although there are morphological variations among Cinnamomum spp., the morphological data alone may not be sufficient to examine the relationships within and between the species. Since environmental factors and environmental plasticity may greatly influence the morphology of plants, reliability of the morphological data is very low (Russell et al., 1993).

In this context, molecular characterization of the plant species would be quite helpful to distinguish the species in terms of taxonomy (Sharma et al., 2008). Numerous molecular techniques have been developed in recent years for visualizing DNA sequence polymorphism. There are a large number of molecular markers; random amplified polymorphic DNA-RAPD (Williams et al., 1990), amplified fragment length polymorphism-AFLP (Vos et al., 1995), simple sequence repeat polymorphism (SSR) and other polymerase chain reaction (PCR) marker systems (Karp et al., 1998). Molecular markers have been used to characterize numerous plants (Karp et al., 1998). RAPD has shown to be a very useful technique for species identification (Abeysinghe et al., 1999; 2000), construction of genetic maps (Tingey \& Del Tufo, 1993),
DNA fingerprinting (Williams et al., 1990; Karp et al., 1998), identification of genetic polymorphism and the parentage determination (Welsh et al., 1991). Sequencerelated amplified polymorphism (SRAP) markers have been used in taxonomy (Ai et al., 2011), genetic diversity analysis in grasses (Budak et al., 2004), breeding (Wu et al., 2011), genetic map construction and gene tagging in Brassica oleracea (Li \& Quiros, 2001) and gene tagging and cloning in B. rapa (Zhang et al., 2009). Molecular markers have been used not only to resolve the fragmentary status of the taxonomy of plant species such as mangroves (Abeysinghe et al., 1999) and other plant species (Bandelj et al., 2002; Arif et al., 2010), but also to distinguish species for breeding purposes and to facilitate conservation (Bardakci, 2001).

Studies have been undertaken to investigate the genetic variation and verify the taxonomic status of the Cinnamomum species at molecular level (Lin et al., 1997; Kojoma et al., 2002; Soulange et al., 2007; Joy \& Maridass, 2008; Kuo et al., 2010; Lee et al., 2010; Ho \& Hung, 2011; Sandigawad \& Patil, 2011; Kameyama, 2012). However, a very few studies have been conducted to study the cinnamon phylogeny in Sri Lanka. Saumyasiri et al. (2006) have studied the phenetic relationships of wild and cultivated accessions of cinnamon in Sri Lanka.

Abeysinghe et al. (2009) have carried out research on the genetic analysis of Cinnamomum species by sequencing $\operatorname{Tr} n \mathrm{~L}$ intron region, intergenic spacers between $\operatorname{trn} \mathrm{T}-\operatorname{trn} \mathrm{L}, \operatorname{trn} \mathrm{L}-\operatorname{trn} \mathrm{F}, \operatorname{trn} \mathrm{H}-\mathrm{psbA}$ and nuclear ITS. This is the only record of a molecular level study of Cinnamomum species in Sri Lanka. There is a germplasm collection of 700 accessions of C. verum from all parts of Sri Lanka maintained at the Cinnamon Research Station, Department of Export Agriculture, Palolpitiya, Thihagoda, Matara, based mainly on some morphological and agronomic characters. It is possible that there may be an undetermined number of duplicates in the collection. Therefore, the aim of this research was to use molecular marker systems to check whether they could be used to study the taxonomy of cinnamon species found in Sri Lanka and to examine whether there is intra-specific variation, which will be useful to screen the $C$. verum accessions of the germplasm for breeding purposes.

\section{METHODS AND MATERIALS}

\section{Collection of plant materials}

From the available Cinnamomum species at the Cinnamon Research Station (CRS) young leaf samples were obtained from two individuals of C. dubium, C. capparu-coronde 
Blume, C. citriodorum, C. litseaefolium, three individuals of $C$. rivulorum and four individuals of $C$. verum and four $C$. verum selected accessions (CRS 357, CRS 23, CRS 184 and CRS 318). As a preliminary study, samples were collected only from the CRS. At the time of collection, young suitable leaf material was not available for $C$. sinharajaense and $C$. ovalifolium. The collected leaf materials were brought to the laboratory of the Department of Botany, University of Ruhuna, Sri Lanka, preserved using silica gel and stored until the DNA was extracted.

\section{DNA extraction and amplification for RAPD}

The DNA was isolated from young silica dried leaf tissues of Cinnamomum species using the hexadecetyltrimethylammonium bromide (CTAB) procedure (Doyle \& Doyle, 1990) with some modifications such as the use of $3 \%$ CTAB and addition of $2 \%$ PVP- polyvynylpyrylidone. Quality and the quantity of extracted DNA were checked on agarose gel. They were non degraded and there was sufficient amount of DNA for PCR. This DNA was used for preliminary RAPD and SRAP analysis. The amplification of genomic DNA was done using 20 RAPD primers from Operon Technology (Alamenda, California, USA). Since there were no molecular data available for Sri Lankan Cinnamomum species for either RAPD or SRAP, primers for PCR were used randomly. The details of each primer are shown in Table 1. PCR was performed according to the protocol of Williams et al. (1990). Initially 20 primers (OPA-07, OPA-15, OPE-01, OPE-07, OPE-09, OPE 14, OPE-15, OPE-16, OPG-14, OPG-15, OPH-11, OPI-01, OPJ-04, OPJ-11, OPJ-12, OPO-06, OPT-06, OPT-12, OPT-15 and OPT-16) (Table 1) were screened using PCR to check whether these primers have the ability to amplify and give reproducible DNA fragments. Two replicates were performed for each PCR. The fragments generated by amplification were resolved on $1.5 \%$ agarose gel and observed under UV illuminator.

\section{PCR amplification for SRAP and fragment analysis}

Twenty six different SRAP primer combinations were used with three different labelled primers: Em1 (red coloured), FC1 (blue coloured) and SA7 (green coloured). With SA7 labelled primer, 8 different unlabelled primers (BG1, BG5, Bg48, BG56, BG62, BG68, BG78 and BG93), with $\mathrm{FC1}, 16$ unlabeled primers (BG1, BG11, BG14, BG15, BG22, BG25, BG48, BG60, BG62, BG66, BG67, BG68, BG73, BG84, BG85, BG93) and with Em1, 2 unlabelled primers (Bg10 and Bg13) were used for the amplification using DNA from 5 Cinnamomum species (4 individuals of $C$. verum, 2 individuals of C. capparu-coronde, C. citriodorum and C. dubium and 3 individuals of $C$. rivulorum). PCR was conducted in a final volume of $10 \mu \mathrm{L}$ and the PCR conditions were as follows; initially denaturing template DNA at $95{ }^{\circ} \mathrm{C}$ for 3 mins followed by the first 5 cycles, which consisted of $50 \mathrm{~s}$ at $95{ }^{\circ} \mathrm{C}$ for template denaturation, $50 \mathrm{~s}$ at $35^{\circ} \mathrm{C}$ for primer annealing and $1 \mathrm{~min}$ at $72^{\circ} \mathrm{C}$ for primer extension. This was followed by 30 cycles; each cycle consisted of $50 \mathrm{~s}$ at $95{ }^{\circ} \mathrm{C}$ for template denaturation, $45 \mathrm{~s}$ at $50{ }^{\circ} \mathrm{C}$ for primer annealing and $1 \mathrm{~min}$ at $72{ }^{\circ} \mathrm{C}$ for primer extension and one cycle of $10 \mathrm{~min}$ for the completion of primer extension. The amplified products were run in an ABI 3100 automated sequencer and analyzed for amplified fragments with different lengths. These different size fragments were analyzed using the Genographer software.

\section{RESULTS}

\section{Primer screening}

In order to screen and select the suitable RAPD primers, DNA from C. dubium and C. capparu-coronde was used for PCR. Size of the fragments obtained for primers were in the range of $\sim 300-\sim 500$ base pair (bp). In this study, fourteen out of the twenty RAPD primers

Table 1: RAPD primers, primer sequences and size of the amplified products

\begin{tabular}{llllll}
\hline Primer & $\begin{array}{l}\text { Primer sequence } \\
5^{\prime} \rightarrow 3^{\prime}\end{array}$ & $\begin{array}{l}\text { Size of the } \\
\text { fragment }\end{array}$ & Primer & $\begin{array}{l}\text { Primer sequence } \\
5^{\prime} \rightarrow 3^{\prime}\end{array}$ & $\begin{array}{l}\text { Size of the } \\
\text { fragment }\end{array}$ \\
\hline OPA-07 & GAAACGGGTG & $>450 \mathrm{bp}$ & OPH-11 & CTTCCGCAGT & Not amplified \\
OPA-15 & TTCCGAACCC & Not amplified & OPI-01 & ACCTGGACAC & Not amplified \\
OPE-01 & CCCAAGGTCC & $>300 \mathrm{bp}$ & OPJ-04 & CCGAACACGG & $>400 \mathrm{bp}$ \\
OPE-07 & AGATGCAGCC & $>350 \mathrm{bp}$ & OPJ-11 & ACTCCTGCGA & $>350 \mathrm{bp}$ \\
OPE-09 & CTTCACCCGA & Not amplified & OPJ-12 & GTCCCGTGGT & $>450 \mathrm{bp}$ \\
OPE-14 & ACTGGGACTC & $>400 \mathrm{bp}$ & OPO-06 & CCACGGGAAG & Not amplified \\
OPE-15 & ACGCACAACC & $>350 \mathrm{bp}$ & OPT-06 & CAAGGGCAGA & $>300 \mathrm{bp}$ \\
OPE-16 & GGTGACTGTG & $>500 \mathrm{bp}$ & OPT-12 & GGGTGTGTAG & $>350 \mathrm{bp}$ \\
OPG 14 & GGATGAGACC & $>450 \mathrm{bp}$ & OPT-15 & GGATGCCACT & $>450 \mathrm{bp}$ \\
OPG-15 & ACTGGGACTC & Not amplified & OPT-16 & GGTGAACGCT & $>300 \mathrm{bp}$ \\
\hline
\end{tabular}




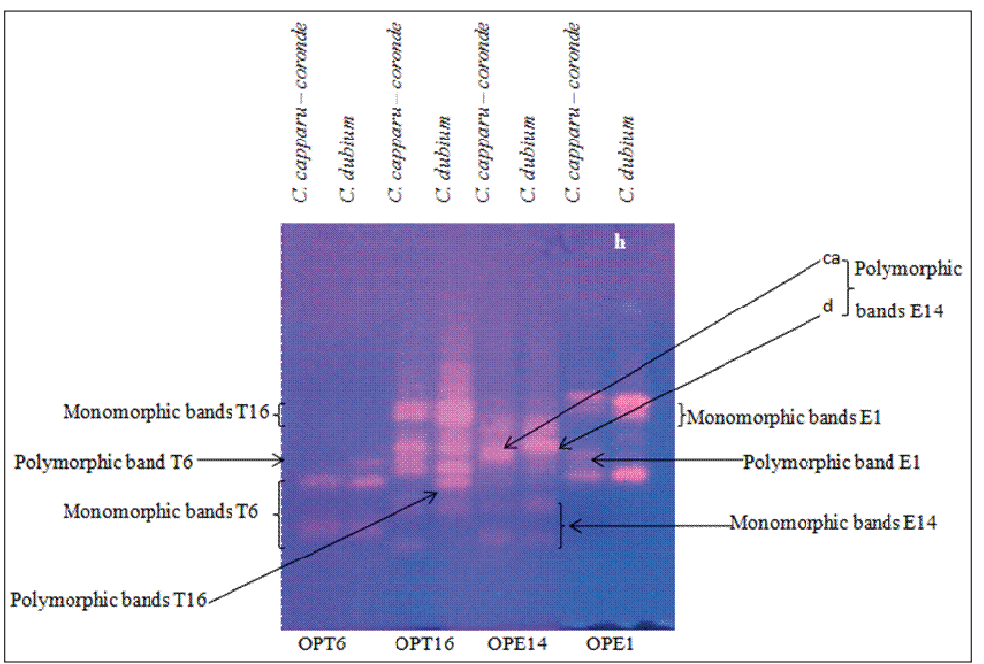

Figure 1: Preliminary screening of RAPD primers: OPT6, OPT16, OPE14 and OPE1 using DNA from C. capparu-coronde (ca) and C. dubium (d)

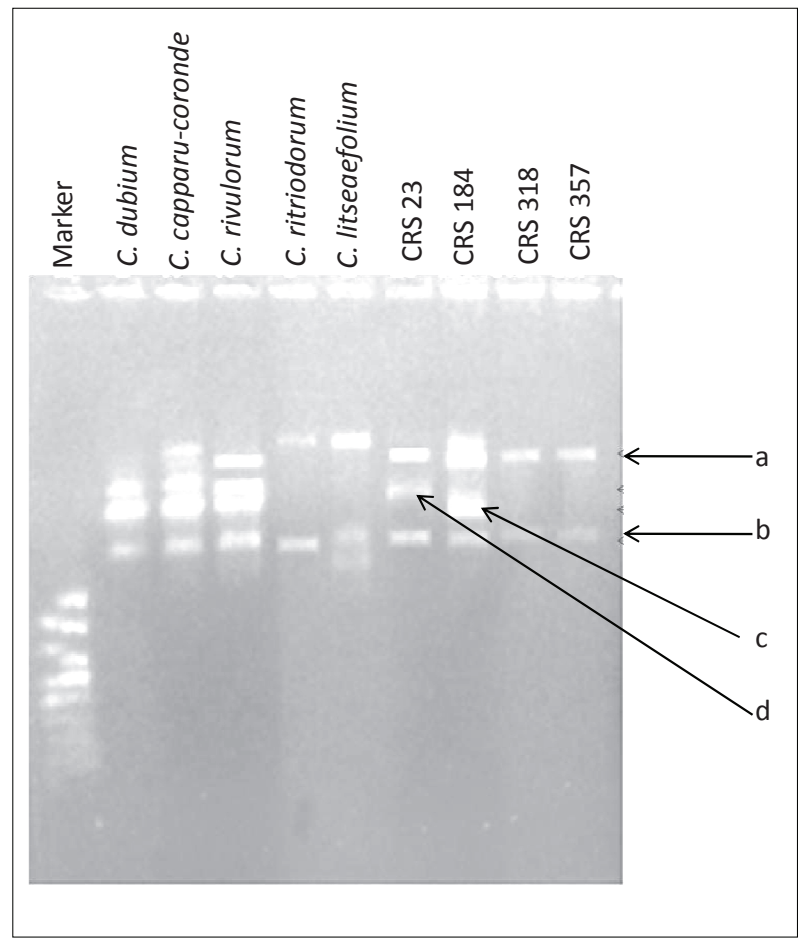

Figure 2: Variation with the RAPD primer OPA-7 of C. dubium, C. capparu-coronde, C. rivulorum, C. citriodorum, C. litseaefolium and C. verum accessions: CRS 23, CRS 184, CRS 318, and CRS 357. Species specific marker a for C. verum and generic specific marker b for all species. c and $\mathrm{d}$ markers could be considered as polymorphic bands for C. verum.

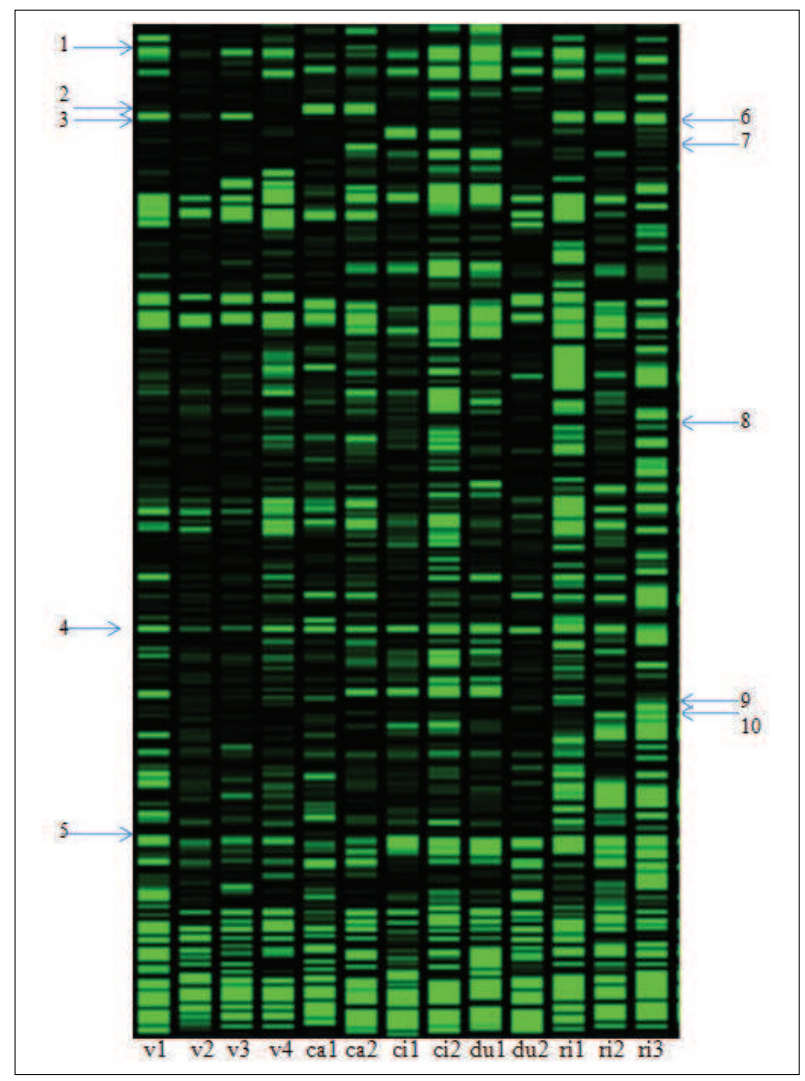

Figure 3: SRAPs amplified by green coloured labelled SA7 and with unlabelled bg48 primers with cinnamon species: v1v3 C. verum individuals, ca1 and ca2 C. capparu-coronde individuals, ci1 and ci2 C. citriodorum individuals, du1 and du2 C. dubium individuals, ri1 and ri2 C. rivulorum individuals. Generic, species or polymorphic markers, 1 10 are shown with arrows. Markers present and absent in Cinnamomum species are tabulated in Table 2. 
tested (Table 1) were able to amplify the genomic DNA and produce scorable bands (polymorphic bands and monomorphic bands) in the tested species. The RAPD patterns were analyzed for polymorphism (Figure 1). The 14 primers namely, OPA-07, OPE-01, OPE-07, OPE 14, OPE-15, OPE-16, OPG-14, OPJ-04, OPJ-11, OPJ-12, OPT-06, OPT-12, OPT-15 and OPT-16 gave amplification products while the others did not give any amplification. The number of fragments generated per primer varied between $2-9$. OPE 14, OPG 14, OPT 06, OPT 15 and OPT 16 primers gave a higher number of polymorphic bands compared to others. The average number of amplification products for species ranged from $2-9$. However, some primers gave highly polymorphic banding patterns, which were more than five scorable bands compared to others primers.

\section{RAPD analysis}

The banding patterns obtained from the preliminary screening with primers, OPT-06, OPT16, OPE14 and OPE-01 is shown in Figure 1. With OPT-06 primer, there is one polymorphic band (T6), which is present in C. dubium but absent in C. capparu-coronde. Therefore,

Table 2: $\quad$ SRAP markers originated from SA7 and with unlabelled bg48 primers

\begin{tabular}{|c|c|c|c|c|c|c|c|c|c|c|c|c|c|c|}
\hline Marker & v1 & v2 & v3 & v4 & cal & $\mathrm{ca} 2$ & ci1 & ci2 & du1 & $\mathrm{du} 2$ & ri1 & ri2 & ri3 & Remarks \\
\hline 1 & + & + & + & + & + & + & + & + & + & + & + & + & + & Generic specific marker \\
\hline 2 & 0 & 0 & 0 & 0 & + & + & 0 & 0 & 0 & 0 & 0 & 0 & 0 & Species specific marker \\
\hline 3 & + & 0 & + & 0 & 0 & 0 & 0 & 0 & 0 & 0 & 0 & 0 & 0 & $\begin{array}{l}\text { Polymorphic marker } \\
\text { for } C \text {. verum }\end{array}$ \\
\hline 4 & + & + & + & + & + & + & + & + & + & + & + & + & + & Generic specific marker \\
\hline 5 & + & + & + & + & + & + & + & + & + & + & + & + & + & Generic specific marker \\
\hline 6 & 0 & 0 & 0 & 0 & 0 & 0 & 0 & 0 & 0 & 0 & + & + & + & $\begin{array}{l}\text { Species specific marker } \\
\text { for } C \text {. rivulorum }\end{array}$ \\
\hline 7 & 0 & 0 & 0 & 0 & 0 & 0 & + & + & 0 & 0 & 0 & 0 & 0 & $\begin{array}{l}\text { Species specific marker } \\
\text { for } C \text {. citriodorum }\end{array}$ \\
\hline 8 & 0 & 0 & 0 & 0 & 0 & 0 & 0 & 0 & 0 & 0 & + & 0 & + & $\begin{array}{l}\text { Polymorphic marker } \\
\text { for } C \text {. rivulorum }\end{array}$ \\
\hline 9 & 0 & 0 & 0 & 0 & 0 & 0 & 0 & 0 & 0 & 0 & 0 & 0 & + & $\begin{array}{l}\text { Polymorphic marker } \\
\text { for } C \text {. rivulorum }\end{array}$ \\
\hline 10 & 0 & 0 & 0 & 0 & 0 & 0 & 0 & 0 & 0 & 0 & 0 & + & + & $\begin{array}{l}\text { Polymorphic marker } \\
\text { for } C \text {. rivulorum }\end{array}$ \\
\hline
\end{tabular}

v1-v3 C. verum individuals, ca1 and ca2 C. capparu-coronde individuals, ci1 and ci2 C. citriodorum individuals, du1 and du2 C. dubium individuals, ri1 and ri2 C. rivulorum individuals

+ indicates the presence of a fragment and 0 indicates the absence of a marker.

this band could be considered as a species specific marker for $C$. dubium. The monomorphic band T6 could be considered as the genus specific marker since it is present in both species. Likewise polymorphic bands T16 and E14d can be considered as the species specific markers for $C$. dubium and polymorphic bands E14ca E1 can be considered as the species specific markers for C. capparucoronde, while monomorphic bands T16 and E14 can be considered as the genus specific markers for both species. According to the preliminary study, monomorphic bands (genus specific) and polymorphic RAPD bands (species specific) were observed. Considering the RAPD products of the primer OPA-07 (Figure 2), species specific marker ' $a$ ' for $C$. verum and genus specific marker ' $b$ ' for all species could be identified. Moreover, polymorphism among the individuals (c and d markers) of the species C. verum could be observed.

\section{SRAP markers for Cinnamomum}

Out of the 26 SRAP primer combinations 4 primer combinations gave the polymorphic banding pattern. These primer combinations produced genus specific, species specific and polymorphic markers for Cinnamomum species (Figure 3 and Table 2). According to Figure 3, SARP has produced more markers per one combination than RAPD. Using this marker system, it was possible to identify the Cinnamomum species and study the genetic diversity. Genus specific, species specific and polymorphic markers or intra-species markers for each species could also be observed (Figure 3 and Table 2). Table 2 shows the genus specific markers (fragments 1 , 4 and 5), species specific marker for C. capparu-coronde (fragment 2- ca1 and ca2), species specific marker for C. rivulorum (fragment 6- ri1, ,ri2 and ri3), species 
specific marker for $C$. citriodorum (fragment $7-$ cil and ci2), and polymorphic marker for $C$. rivulorum (fragments 8, 9 and 10).

\section{DISCUSSION}

The foremost objective of this research was to study the variation of Cinnamomum species at DNA level. By employing different oligonucleotide primers (RAPD primers), molecular markers can be generated that are diagnostic at different taxanomic levels. For any given primer, RAPD amplification products can be broadly classified into two groups: variable (polymorphic) or constant (non-polymorphic). These definitions are relative for a given taxanomic unit (OTU) (Hadrys et al., 1992). Similar kinds of RAPD products were observed in this study. Although RAPD has some disadvantages such as co-migration of different size fragments and reproducibility problems, RAPD markers have been applied in cultivar identification (Cabrita et al., 2001), parentage determination (Elisiàrio et al., 1999) and identification of inter-specific hybrids (Lee et al., 2006; Saitou et al., 2007).

The RAPD analysis of individuals within the species C. verum (CRS23, CRS184, CRS318 and CRS357) and six species within the genus $(C$. verum, C. capparucoronde, C. citriodorum, C. dubium, and C. rivulorum) has identified constant fragments diagnostic for a genus. Therefore, these genus specific fragments can serve as diagnostic DNA markers in RAPD analyses. The species specific fragment is identified by its presence in all the individuals of C. verum (CRS23, CRS184, CRS318 and CRS357). By employing fragments that are polymorphic among the individuals, RAPD analysis could be used to assess the diversity of Cinnamomum species.

Genetic markers with RAPD are obtained for the identification of polymorphism based upon the existence of polymorphic RAPD bands. Therefore, it is important to identify as many RAPD bands as possible. High degree of polymorphism observed indicates a potential for selection and availability as a genetic source (Bandelj et al., 2002). Therefore, RAPD primers OPE-14, OPG14, OPT-06, OPT-15, and OPT-16 can be used for further studies to detect polymorphism in Cinnamomum spp. It is however essential to carry out more research using all species with more samples, as well as with replicates (at least two) for each primer to get more polymorphic bands (variation) in order to conclude the delimitation of Cinnamomum spp. This study was carried out as a preliminary primer screening for the available leaf samples of Cinnamomum species during the collection of samples for DNA extraction. Therefore, further research should be carried out to study the variation of Cinnamomum species with expanded sampling of individuals of each species in order to get a better picture of the species relationship.

Another PCR based technique, SRAP was used to check whether this technique can be utilized to identify the Cinnamomum species, and to study the diversity of Cinnamomum species found in Sri Lanka. In this study five Cinnamomum species (C. verum, C. capparucoronde, C. citriodorum, C. dubium and C. rivulorum) found in Sri Lanka was investigated using SRAP markers. Out of the 26 SRAP primer combinations 4 primer combinations amplified the DNA producing large number of markers per one primer combination. This preliminary study showed that using these molecular markers, it is possible to identify the Cinnamomum species (genus specific and species specific) and intraspecies variations. Since both molecular marker systems gave genus specific and species specific markers, these markers could be used to identify the Cinnamomum species correctly. Both RAPD and SRAP markers gave intra-specific polymorphic banding patterns among the individuals of $C$. verum, and this marker system could be used to screen the 700 accessions present at the Cinnamon Research Station, Department of Export Agriculture, Palolpitiya, Thihagoda, Matara, Sri Lanka to examine their genetic relatedness. However, before the screening of the germplasm, it is necessary to select more reliable and consistent RAPD and SRAP markers.

The results generated by molecular studies are in agreement with previous morphology-based analysis (Wijesinghe et al., 2004). The existence of intermediate forms blurs the inter-specific and intra-specific relationships within the Cinnamomum genus and it has proven difficult to resolve or to distinguish species using only morphological characters. Therefore, this study contributes new molecular data for the identification of different species of Cinnamomum that have not been used for molecular marker analysis.

An earlier investigation of the diversity of Cinnamomum species (C. verum, $C$. citriodorum, C. capparu-coronde, C. dubium, C. litseafolium, C. rivulorum, $C$. sinharajanse and $C$. camphora) found in Sri Lanka has been conducted by sequencing the different regions of chloroplast spacer regions of $\operatorname{Tr} n \mathrm{~L}$ intron region, intergenic spacers between $\operatorname{trn} \mathrm{T}-\operatorname{trn} \mathrm{L}, \operatorname{trn} \mathrm{L}$ $\operatorname{trn} \mathrm{F}$ and nuclear ITS region of the rDNA (Abeysinghe et al., 2009). One mutation at each $\operatorname{trn} \mathrm{L}-\operatorname{trn} \mathrm{F}$ and $\operatorname{trn} \mathrm{T}-$ trnL-IGS regions was deteced while four mutation sites were observed in trnL intron. The length of the amplified products of trnL UAA intron, intergenic spacers (IGS) of 
$\operatorname{trn} \mathrm{L}-t r n \mathrm{~F}$ and $\operatorname{trn} \mathrm{T}-\operatorname{trn} \mathrm{L}$ were approximately $400-600$ bp. Since much variations were not observed among the cpDNA regions studied, the two molecular marker systems (RAPD and SRAP) were employed in order to clarify the taxonomy status of cinnamon species found in Sri Lanka.

\section{Acknowledgement}

The authors thank The Association of Commonwealth Universities Titular Fellowship (DF-2008-15) and research grants $\mathrm{RU} / \mathrm{SF} / \mathrm{RP} / 2001 / 05$ and $\mathrm{RU} / \mathrm{SF} /$ RP/2009/05 awarded from the Faculty of Science, University of Ruhuna, Sri Lanka to carry out this research.

\section{REFERENCES}

1. Abeysinghe P.D., Triest L., De Greef B., Koedam N. \& Hettiarachi S. (1999). Genetic differentiation between Bruguiera gymnorhiza and B. sexangula in Sri Lanka. Hydrobiologia 413: 11 - 16.

DOI: http://dx.doi.org/10.1023/A:1003899028558

2. Abeysinghe P.D., Triest L., De Greef B., Koedam N. \& Hettiarachi S. (2000). Genetic and geographic variation of the mangrove tree Bruguiera in Sri Lanka. Aquatic Botany 67: $131-141$.

DOI: http://dx.doi.org/10.1016/S0304-3770(99)00096-0

3. Abeysinghe P.D., Wijesinghe K.G.G., Tachida H. \& Yoshda T. (2009). Molecular characterization of cinnamon (Cinnamomum verum Presl) accessions and evaluation of genetic relatedness of Cinnamon species in Sri Lanka based on $\operatorname{trn} \mathrm{L}$ intron region, intergenic spacers between trn T-trnL, trnL-trnF trn $\mathrm{H}-p s b \mathrm{~A}$ and nuclear ITS. Research Journal of Agriculture and Biological Sciences 5: 1079 1088.

4. Ai P.F., Zhen Z.J. \& Jin Z.Z. (2011). Genetic diversity and relationships within sweet kernel apricot and related Armeniaca species based on sequence-related amplified polymorphism markers. Biochemical Systematics and Ecology 39: 694 - 699.

DOI: http://dx.doi.org/10.1016/j.bse.2011.05.026

5. Anon D. (2006). Administrative Report. Department of Export Agriculture, Peradeniya.

6. Arif I.A., Bakir M., Khan H.A., Al Farhan A.H., Al Homaidan A.A., Bahkali A.H., Al Sadoon M. \& Shobrak M. (2010). Application of RAPD for molecular characterization of plant species of medicinal value from an arid environment. Genetics and Molecular Research 9: $2191-2198$.

DOI: http://dx.doi.org/10.4238/vol9-4gmr848

7. Bandelj D., Jakse J. \& Javornik B. (2002). DNA fingerprinting of olive varieties by microsatellite markers. Food Technology and Biotechnology 40: 185 - 190.

8. Bardakci F. (2001). Random amplified polymorphic DNA (RAPD) markers. Turkish Journal of Biology 25: 185 196.
9. Bruno G. (2009). Cinnamon: a supplement for diabetes, body composition, cardiovascular health and antioxidant protection. Literature Education Series on Dietary Supplements. Huntington College of Health Sciences, Knoxville, USA.

10. Budak H.R.C., Shearman I., Parmaksiz R.E., Gaussoin T.P. \& Riosdan D. (2004). Molecular characterization of Buffalograss germplasm using sequence-related amplified polymorphism markers. Theoretical and Applied Genetics 108: $328-334$.

DOI: http://dx.doi.org/10.1007/s00122-003-1428-4

11. Cabrita L.F., Aksoy U., Hepaksoy S. \& Leitão J.M. (2001). Suitability of isozyme RAPD and AFLP markers to assess genetic differences and relatedness among fig (Ficus carica L.) clones. Scientia Horticulturae 87: 261 - 273.

DOI: http://dx.doi.org/10.1016/S0304-4238(00)00181-3

12. Dassanayaka M.D., Fosberg F.R. \& Clayton W.D. (eds) (1995). A Revised Handbook to the Flora of Ceylon, pp. 105. Amerind Publishing Co. Pvt. Ltd., New Delhi, India.

13. Dighe V.V., Gursale A.A., Sane R.T., Menon S. \& Raje S.C. (2005). Quantification of eugenol in Cinnamomum tamala Neesand Eberm. leaf powder by high-performance thinlayer chromatography. Journal of Planar Chromatography 18: $305-307$.

14. Doyle J.J. \& Doyle J.L. (1990). Isolation of plant DNA from fresh tissue. Focus 12: 13-15.

15. Elisiàrio P.J., Justo E.M. \& Leitao J.M. (1999). Identification of mandarin hybrids by isozyme and RAPD analysis. Scientia Horticulturae 81: 287 - 299.

16. Hadrys H., Balick M. \& Schierwater B. (1992). Applications of random amplified polymorphic DNA (RAPD) in molecular ecology. Molecular Ecology 1(1): 55 - 63. DOI: http://dx.doi.org/10.1111/j.1365-294X.1992.tb00155.x

17. Ho K.Y. \& Hung T.Y. (2011). Cladistic relationships within the genus Cinnamomum (Lauraceae) in Taiwan based on analysis of leaf morphology and inter-simple sequence repeat (ISSR) and internal transcribed spacer (ITS) molecular markers. African Journal of Biotechnology 10: $4802-4815$.

18. Joshep J. (1981). Floral biology and variation in cinnamon, Proceedings of the $4^{\text {th }}$ Plantation Crops Symposium (Placrosym), The Indian Society for Plantation Crops, Central Plantation Crops Research Institute, Kasaragod, India, pp. $431-434$.

19. Joy P. \& Maridass M. (2008). Inter species relationship of Cinnamomum species using RAPD marker analysis. Ethnobotanical Leaflets 12: 476 - 480.

20. Kameyama Y. (2012). Development of microsatellite markers for Cinnamomum camphora (Lauraceae). American Journal of Botany 99(1): e1 - e3. DOI: http://dx.doi.org/10.3732/ajb.1100231

21. Karp A., Isaac P.G. \& Ingram D.S. (1998). Molecular Tools for Screening Biodiversity - Plants and Animals, pp. $498-$ 520. Chapman \& Hall Publishers, London, UK.

22. Khan A., Safdar M., Ali Khan M.M., Khattak K.N. \& Anderson R.A. (2003). Cinnamon improves glucose and lipids of people with type 2 diabetes. Diabetes Care 26: 3215 - 3218.

DOI: http://dx.doi.org/10.2337/diacare.26.12.3215 
23. Kojoma M., Kurihara K., Yamada K., Sekita S., Satake M. \& Lida O. (2002). Genetic identification of Cinnamon spp. based on the trnL-trnF chloroplast DNA. Planta Medica 68: $94-96$.

DOI: http://dx.doi.org/10.1055/s-2002-20051

24. Kostermans A.J.G.H. (1995). Lauraceae. A Revised Handbook to the Flora of Ceylon (eds. M.D. Dassanayaka F. Fosberg \& W.D. Clayton), volume IX, pp. 112 - 129. Amerind Publishing Co. Pvt. Ltd., New Delhi, India.

25. Krishnamoorthy B., Sasikumar B., Johnson R.J., George K. \& Peter K.V. (1997). Genetic resources of tree spices and their conservation in India. Plant Genetic Resources News Letters 111: 53 - 58.

26. Kumarathilake D.M.H.C., Senanayake S.G.J.N., Wijesekara G.A.W., Wijesundera D.S.A. \& Ranawaka R.A.A.K. (2010). Extinction risk assessments at the species level: national red list status of endemic wild cinnamon species in Sri Lanka. Tropical Agriculture Research 21: $247-257$.

27. Kuo D.C., Lin C.C., Ho K.C., Cheng Y.P., Hwang S.Y. \& Lin T.P. (2010). Two genetic divergence centers revealed by chloroplastic DNA variation in populations of Cinnamomum kanehirae Hay. Conservation Genetics 11: $803-812$.

DOI: http://dx.doi.org/10.1007/s10592-009-9901-5

28. Lee N.S., Yeau S.H., Park J.O. \& Roh M.S. (2006). Molecular evidence for hybridization of Ilex xwandoensis (Aquifoliaceae) by RAPD analysis. Journal of Plant Biology 49: 491 - 497.

DOI: http://dx.doi.org/10.1007/BF03031131

29. Lee S.C., Lee C.H., Yilin M. \& Ho K.Y. (2010). Genetic identification of Cinnamomum species based on partial internal transcribed spacer 2 of ribosomal DNA. Journal of Food and Drug Analysis 18: 225 - 231.

30. Li G. \& Quiros C.F. (2001). Sequence-related amplified polymorphism (SRAP), a new marker system based on a simple PCR reaction: its application to mapping and gene tagging in Brassica. Theoretical and Applied Genetics 103: $455-461$.

DOI: http://dx.doi.org/10.1007/s001220100570

31. Lin T.P., Cheng Y.P. \& Huang S.G. (1997). Allozyme variation in four geographic areas of Cinnamomum kanehlrae. Journal of Heredity 88: 433 - 438.

DOI: http://dx.doi.org/10.1093/oxfordjournals.jhered.a023 131

32. Russell J.R., Hosein F., Johnson E., Waugh R. \& Powell W. (1993). Genetic differentiation of cocoa, Theobroma cacao L. populations revealed by RAPD analysis. Molecular Ecology 2: 289 - 297.

DOI: http://dx.doi.org/10.1111/j.1365-294X.1993.tb00003.x

33. Saitou K., Fukuda T. \& Yokoyama J. (2007). Morphological and molecular (RAPD) analyses confirm the hybridorigin of the diploid grass Calamagrostis Longiseta var. longearistata (Gramineae). Folia Geobotanica 42: 63 - 76. DOI: http://dx.doi.org/10.1007/BF02835102

34. Sandigawad A.M. \& Patil C.G. (2011). Genetic diversity in Cinnamomum zeylanicum Blume. (Lauraceae) using random amplified polymorphic DNA (RAPD) markers. African Journal of Biotechnology 10: 3682 - 3688.
35. Saumyasiri M.M.K.G., Yakandawala D.M.D., Samaraweera P. \& Wijesinghe K.G.G. (2006). Phylogenetic relationship of Cinnamomum species in Sri Lanka. Proceedings of the $11^{\text {th }}$ Peradeniya University Research Sessions, 30 November, p. 134.

36. Sharma A., Namdeo A.G. \& Mahadik K.R. (2008). Molecular markers: new prospects in plant genome analysis. Pharmacognosy 2: $23-34$.

37. Smerq J. \& Sharma M. (2011). Possible mechanism of Murraya koenigii and Cinnamomum tamala with reference to antioxidants activity. International Journal of Pharmaceutical Science and Drug Research 3: 260 264.

38. Soulange J.G., Sanmukhiya V.M.R. \& Seeburrun S.D. (2007). Tissue culture and RAPD analysis of Cinnamomum camphora and Cinnamomum verum. Biotechnology 6: 239 $-244$.

DOI: http://dx.doi.org/10.3923/biotech.2007.239.244

39. Sritharan R. (1984). The study of the genus Cinnamomum. M. Phil thesis, Postgraduate Institute of Agriculture, University of Peradeniya, Peradeniya.

40. Tingey S.V. \& Del Tufo J.P. (1993). Genetic analysis with random amplified polymorphic DNA markers. Plant Physiology 101: 349 - 352.

DOI: http://dx.doi.org/10.1104/pp.101.2.349

41. Vos P., Hogers R., Bleeker M., Reijans M., van de Lee T., Hornes M., Frijters A., Pot J., Peleman J. \& Kuiper M. (1995). AFLP: a new technique for DNA fingerprinting. Nucleic Acids Research 23: 4407 - 4414.

DOI: http://dx.doi.org/10.1093/nar/23.21.4407

42. Welsh J., Honeycutt R.J., McClelland M. \& Sobral B.W.S. (1991). Parentage determination in maize hybrids using the arbitrarily primed polymerase chain reaction (AP-PCR). Theoretical and Applied Genetics 82: 473 - 476. DOI: http://dx.doi.org/10.1007/BF00588601

43. Wijesinghe K.G.G., Samaraweera D.N., Jayasinghe D. \& Gunaratna G.G. (2004). Development of cinnamon (Cinnamomum verum Presl) selection for higher yields with better quality characteristics. CARP Competitive Contract Research Grants Programme (eds. H.P.M. Gunasena, M.P. Dhanapala \& T.U. Tillekawardana), pp 3 - 10. Sri Lanka Council for Agricultural Research Policy, Wijerama Mawatha, Colombo 07.

44. Williams J.G.K., Kubelik A.R., Livak K.J., Rafalski J.A. \& Tingey S.V. (1990). DNA polymorphisms amplified by arbitrary primers are useful as genetic markers. Nucleic Acids Research 18: 6531 - 6535.

DOI: http://dx.doi.org/10.1093/nar/18.22.6531

45. Wu Z., Ning W., Wang Y., Lv S., Zhao Y. \& Zhao X. (2011). Genetic diversity of taraxacum germplasm revealed by sequence-related amplified polymorphism (SRAP) analysis. African Journal of Biotechnology 10: 9557 9562.

46. Zhang J., Lu Y., Yuan Y., Zhang X., Geng J., Chen Y., Cloutier S., Mc Vetty P.B.E. \& Li G. (2009). Mapbased cloning and characterization of a gene controlling hairiness and seed coat color traits in Brassica rapa. Plant Molecular Biology 69: 553 - 563.

DOI: http://dx.doi.org/10.1007/s11103-008-9437-y 